\title{
Detection of Functional Changes of the Fetal Heart in the First Trimester of Gestation
}

\author{
Carlos Geraldo Viana Murta, Antônio Fernandes Moron, Márcio Augusto Pinto de Ávila \\ São Paulo, SP - Brazil
}

\begin{abstract}
The authors consider the possibility of using color Doppler of the ductus venosus and the measurement of nuchal translucency as a screening test for alterations in fetal cardiac functions in the first trimester of gestation. Review of the literature suggests that the combination of the ultrasonographic measurement of nuchal translucency and Doppler at 10 and 14 weeks of gestation can be effective in detecting certain cardiac abnormalities. This conclusion, however, is preliminary and needs to be further investigated.
\end{abstract}

It is almost always impossible to assess cardiac function and anatomy in the first trimester of gestation. Montenegro et al ${ }^{1}$ propose the study by Doppler of the venous return to the heart in an attempt to indirectly measure cardiac function.

The main organs determining fetal hemodynamics are the heart and the placenta. Two types of circulation unite these organs: on one side, the venous circulation, and on the other, the arterial circulation. Both circulations can be altered by changes at the placental, cardiac, central nervous system, and peripheric levels. In the literature, however, there is a paradoxical overestimation of the value of the arterial blood flow. Only recently has the venous blood flow been explored. Eik-Nes et $\mathrm{al}^{2}$ and $\mathrm{Gill}_{\mathrm{e}}$ et $\mathrm{al}^{3}$ published, for the first time, a Doppler velocimetry of the umbilical venous flow. In 1983, Griffin, Cohen-Overbeek and Campbell ${ }^{4}$ studied the inferior vena cava. In 1991, Kiserud et al ${ }^{5}$ published the first study of the human fetal ductus venosus.

At the end of the $4^{\text {th }}$ week of gestation, the heartbeats of the embryo begin. The heart, whose development starts at the $3^{\text {rd }}$ week of gestation, has rapid and irregular contractions capable of pumping the blood inside the vessels. At this period, the developing circulatory system allows maternal-embryonic nutritive and gaseous changes at the chorionic villi. It is well documented in the literature that, in healthy fetuses, the heart rate (HR) increases from $110 \mathrm{bpm}$ at the $5^{\text {th }}$ week of gestation to $170 \mathrm{bpm}$ at the $9^{\text {th }}$ week of

Universidade Federal de São Paulo - Escola Paulista de Medicina Mailing address: Carlos G. V. Murta - Vitória MedfetUS - Av. César Hilal - 1181/ 401 - 29052-231 - Vitória - ES - Brazil gestation. From then on, there is a gradual reduction in the HR that reaches a mean value of $150 \mathrm{bpm}$ at the $13^{\text {th }}$ week of gestation. The initial elevation of the HR coincides with the morphological development of the heart, and the subsequent decline can result from the functional maturation of the parasympathetic nervous system ${ }^{6}$.

There is evidence that cardiac dysfunction can be indirectly detected through the assessment of the velocimetry of the ductus venosus and the measurement of the nuchal translucency (NT) between the $10^{\text {th }}$ and $14^{\text {th }}$ weeks of gestation ${ }^{1}$.

\section{Nuchal translucency}

High-resolution ultrasonography is capable of detecting a thin translucent layer between the skin and the subcutaneous tissue that covers the cervical backbone. This hypoechoic area can be routinely seen at the end of the first and beginning of the second trimester of gestation. It was named nuchal translucency (NT) due to its ultrasonographic quality.

Several studies have shown a significant increase in NT between the $10^{\text {th }}$ and $14^{\text {th }}$ weeks of gestation in chromosomal ${ }^{7,8}$ and cardiac ${ }^{9,10}$ abnormalities. These studies emphasize that, in case of adequate training of the person performing the procedure, this new method can screen fetal abnormalities of the heart and great vessels in the first trimester of gestation. The exam can be performed through vaginal or abdominal via, depending on the fetal position and gestational age. The greater the NT, the higher the possibility of cardiac abnormality ${ }^{9}$.

The physiological bases to explain this transient ultrasonographic marker (NT) are not yet well understood. Some events occurring in the first trimester of gestation could, eventually, explain the transient accumulation of fluids in the fetal nuchal area. One possible cause is an alteration in the fetal lymphatic drainage and/or, particularly, a transient cardiac hemodynamic dysfunction proper for that gestational age. In normal fetuses, at this stage of intrauterine development, a narrowing of the isthmus of aorta can be seen ${ }^{10}$.

According to Hyett et al ${ }^{10}$, the narrower isthmus of aorta causes a differential in pressure between the ascen- 
ding and descending aorta, resulting in an increase in the perfusion of the fetal head and neck. This causes congestion and edema of the nuchal area and its volume may vary according to the difficulty of drainage.

Wladimiroff et al ${ }^{11}$ showed that, between the $11^{\text {th }}$ and the $13^{\text {th }}$ weeks of gestation, the resistance to the flow in the cerebral arteries is lower than that observed in the descending aorta. At the end of the $2^{\text {nd }}$ gestational trimester, a slight reduction in the resistance of the cerebral vessels is observed, contrasting with the accentuated reduction in the resistance of the aorta and umbilical arteries. These velocimetric changes, however, result from placentary vascular alterations proper at this stage of pregnancy ${ }^{11}$. Based on these studies, NT may originate from a hemodynamic adaptation during the cardiovascular development, emphasizing the point that the concomitance of tachycardia and an increase in NT is common. This tachycardia may result from the delay in the maturing process of the fetal parasympathetic system ${ }^{6}$.

In conclusion, some kind of anatomical or physiological alteration of the fetal heart and great vessels, between the $10^{\text {th }}$ and $14^{\text {th }}$ weeks of gestation, is the main cause of the nuchal edema. Blood would have difficulty in flowing through the heart; this increase in the cardiac work, although transitory, would reflect in the preload (central venous flow), overloading it. This might perhaps justify the accumulation of fluid in the cervical area and, in addition, cause a possible alteration in the velocity waveform of the flow of the venous vessels, particularly of the ductus venosus.

\section{Doppler study of the ductus venosus}

The main vessels in the assessment of the venous return in the human fetus are the inferior vena cava and the vessels of the venous vascularization of the fetal liver (umbilical vein, portal veins, hepatic veins and ductus venosus) ${ }^{12}$. When the umbilical vein enters the abdomen, it assumes a more horizontal position and a posterior direction; then it shifts to the right, where it merges with the left portal vein and continues as the right portal vein with its anterior and posterior divisions. Before shifting to the right, the ductus venosus rises, and its diameter is approximately $1 / 3$ that of the umbilical vein. The ductus has a posterior trajectory with a cephalic direction. Right after emerging from the liver, it runs into the inferior vena cava, immediately below the diaphragm, where the left, right and middle hepatic veins also drain. This region of the inferior vena cava has been named the fetal subdiaphragmatic venous vestibulum ${ }^{13}$.

The ideal echographic plane to visualize the ductus venosus in its larger extension is the medium-sagittal longitudinal section of the fetal trunk. The origin of the ductus venosus can also be identified through a transversal (slightly oblique) section of the superior part of the fetal abdomen. At the origin of the ductus venosus, the blood coming through the umbilical vein changes its tone, which becomes lighter, indicating a higher flow velocity.
The fetus has three anatomical derivations of its circulation to modify the direction of the blood flow to avoid the mixture between the oxygenated flow, coming from the placenta, and that of low saturation, which returns to the heart.

Approximately $50 \%$ of the oxygenated blood of the umbilical vein enters the venous hepatorenal system and the remaining runs to the thoracic inferior vena cava through the ductus venosus (first derivation). Therefore, the saturation of hemoglobin is the same in the ductus venosus and in the umbilical vein ${ }^{12}$.

Blood coming from the abdominal inferior vena cava, which represents $65 \%$ to $70 \%$ of the venous return to the heart, does not mix with the well oxygenated blood flow coming from the ductus venosus when they meet at the thoracic inferior vena cava. This results from the increase in velocity and the higher saturation in oxygen of the blood coming from the ductus venosus. In the right atrium (RA), the richly oxygenated blood derived from the ductus venosus flows in a preferential way through the fossa ovalis ( $2^{\text {nd }}$ derivation) into the left atrium, joining the small amount of blood coming from the pulmonary veins. This way, the well oxygenated blood flows to the left ventricle and, from there, it is distributed to the noble organs (myocardium and brain) and to the upper limbs ${ }^{14}$. According to Hecher and Campbell ${ }^{12}$, data in the literature are conflicting in regard to the existence of a sphincter (isolated muscle structure) regulating the blood flow in the ductus venosus. It has already been demonstrated, however, that the autonomous nervous system influences the regulation of this flow ${ }^{15}$.

The rest of the blood flow in the inferior vena cava (coming from the liver and the lower limbs) united to that of the superior vena cava in the RA, goes to the right ventricle (RV) and enters the pulmonary artery. However, in a higher volume, it reaches the descending aorta through the $3^{\text {rd }} \mathrm{de}-$ rivation of the fetal circulation (ductus arteriosus). Blood of the descending aorta, with low oxygen saturation, returns to the placenta via the umbilical arteries to be reoxygenated ${ }^{16}$.

The ductus venosus is one of the three exclusive derivations of the fetal circulation that has the function of directly conducting the well-oxygenated blood from the umbilical vein to the heart. Through the use of the color Doppler, the ductus venosus is visualized as a small and narrow vessel, which has a high-velocity flow, similar to that of the arteries. This increased velocity of the blood in the ductus venosus makes it possible to reach the oval foramen without mixing with the remaining poorly oxygenated flow in the RA ${ }^{5}$.

The velocimetric study of the ductus venosus was introduced by Kiserud et $\mathrm{al}^{5}$, in 1991, and Huisman et $\mathrm{al}^{17}$, in 1992, allowing new uses of Doppler in obstetrics. These authors showed, in a normal pregnancy, a 2- to 4-fold increase in the blood flow velocity as it enters the ductus venosus. Therefore, blood inside this vessel has a brilliant color and a light tone, causing a difference in tonality in relation to the umbilical vein flow. This characteristic favors 
the identification of the ductus venosus blood flow using the color Doppler. Gennser ${ }^{18}$ reports that in the junction of the umbilical vein and the ductus venosus (isthmic region), there is a small muscle sphincter that regulates the blood flow entering the ductus. This sphincter would also cause the occlusion of the ductus after birth ${ }^{16}$.

Figure 1 shows that the ductus venosus blood flow velocity waveform is unidirectional and biphasic. The first peak arises during the ventricular systole (S) and the second during the ventricular diastole (D). The notch between two cycles represents the end of the diastole and the atrial contraction (a).

Montenegro et al ${ }^{19}$ studied the ductus venosus blood flow velocity waveform in normal pregnancies between the $10^{\text {th }}$ and $13^{\text {th }}$ weeks of gestation. They did not find any significant variation in the analyzed parameters, which remained constant. The value of the maximum velocity during systole was $24.8(+/-10.0) \mathrm{cm} / \mathrm{s}$, during diastole it was $18.8(+/-8.4) \mathrm{cm} / \mathrm{s}$ and the time of the mean velocity (TAV) was $16.5(+/-2.0) \mathrm{cm} / \mathrm{s}$. The mean value of the maximum velocity during the atrial contraction was $3.4(+/-1.9)$ $\mathrm{cm} / \mathrm{s}$. The pulsatility index (PI) also remained constant during this period $(1.3+/-0.2)$. The authors conclude that changes in the velocities of the different components of the ductus venosus blood flow velocity waveform occur after this period, as Wladimiroff and Huisman demonstrated ${ }^{20}$.
Wladimiroff and Huisman ${ }^{20}$ evaluated the ductus venosus velocimetry by Doppler echocardiography between the $19^{\text {th }}$ and the $39^{\text {th }}$ weeks of gestation. They observed that with the progression of the gestation, there was an increase in the TAV, in the peak of the systolic and diastolic maximum velocities, but the $\mathrm{S} / \mathrm{D}$ ratio remained constant. They concluded that these findings were due to an increase in the blood flow and in the contractility, to the cardiac compliance and to the reduction in the afterload. The last one is very well established because of the physiological reduction in the placentary vascular resistance in the $2^{\text {nd }}$ trimester of gestation ${ }^{21}$.

Concomitant with the changes in the pattern of flow of the ductus venosus, Wladimiroff and Huisman ${ }^{20}$ observed that, during fetal activity, there is an increase of $30 \%$ in the velocities during systole and diastole, when compared with values when the fetal is sleeping. According to the authors, fetal activity may require a greater amount of well-oxygenated blood inside the right chambers of the heart.

Van Splunder et al ${ }^{22}$ studied through Doppler echocardiography the inferior vena cava, the ductus venosus and the umbilical vein of 262 fetuses between the $8^{\text {th }}$ and the $20^{\text {th }}$ weeks of gestation. In the umbilical vein, they found the venous pulsation as the normal pattern until the $15^{\text {th }}$ week; the venous pulsatility index (VPI) decreased linearly and TAV increased with the gestational age. In the ductus

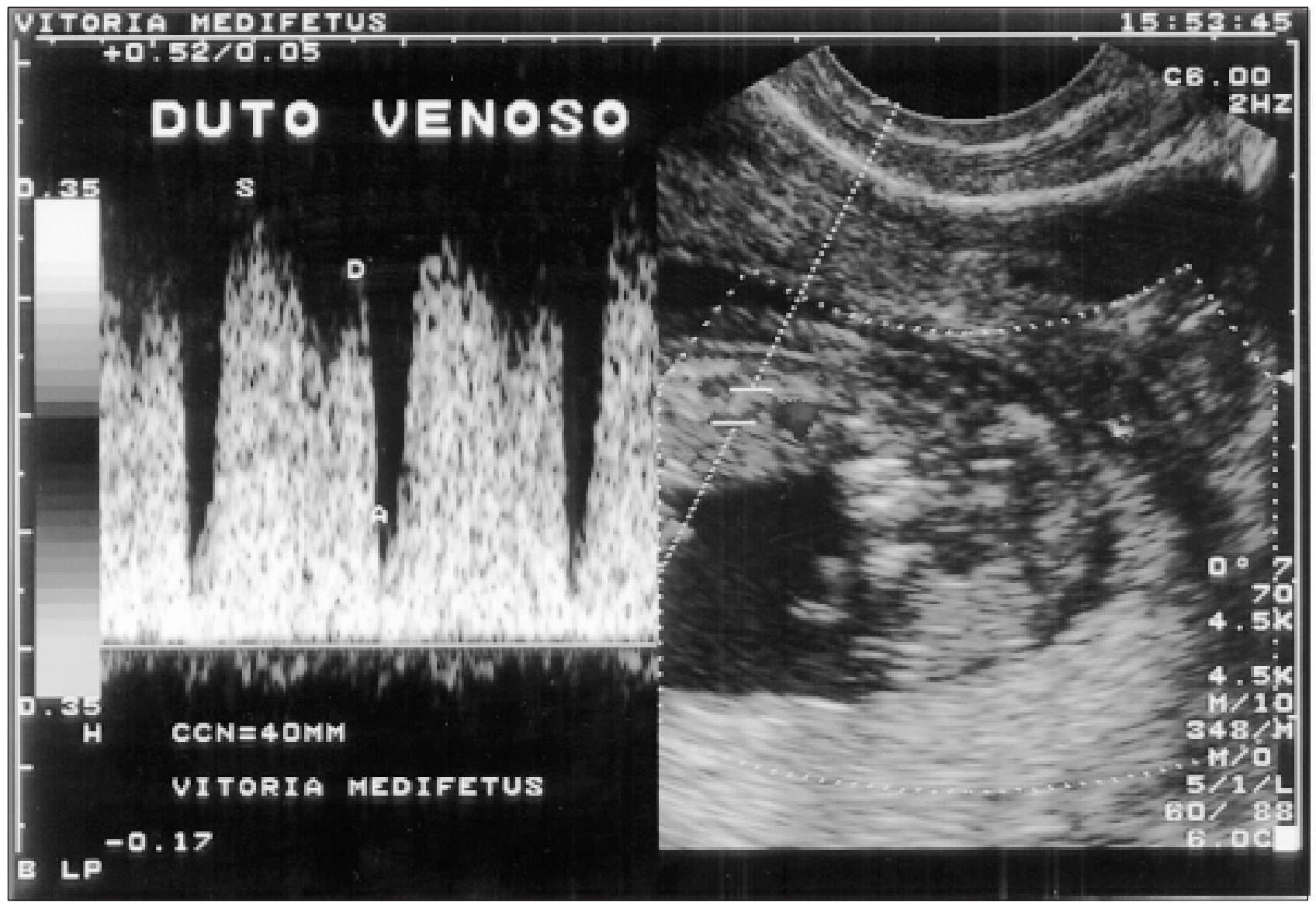

Fig. 1 - Ductus venosus blood flow velocity waveform at the $11^{\text {th }}$ week of gestation (crown-rump length of $40 \mathrm{~mm}$ ). The exam was performed through the vaginal via. 
venosus, in addition to the increase in TAV, there was an increase in the maximum velocity during systole and diastole, as well as in the inferior vena cava. On the other hand, in both vessels, there was a decrease in the VPI with the progression of the gestation. The percentage of reverse flow in the inferior vena cava remained constant until the $14^{\text {th }}$ week, and from then on it decreased considerably. They did not mention the behavior of the minimum velocity in the ductus venosus during atrial contraction. The ductus venosus blood flow velocity waveform was identified from the $9^{\text {th }}$ week on, since the anatomical development of this vessel is complete by the $8^{\text {th }}$ week. The inferior vena cava blood flow velocity waveform can be studied from the $8^{\text {th }}$ week on. The increase in TAV with the gestational age was observed in the three vessels studied in the proportion of 2 , 3 and 4 times, respectively, for the inferior vena cava, the umbilical vein and the ductus venosus. Therefore, the ductus venosus was the vessel with the highest increase in velocity of flow, a finding that can support the existence and development of the sphincter in this vessel.

Preliminary studies ${ }^{5,17}$ showed, in normal gestations, a 2- to 4-fold increase in the velocity of blood flow when entering the ductus venosus. This increase in velocity may be due to the presence of the already mentioned sphincter between the umbilical vein and the ductus venosus (isthmic region) and also to the pressure gradient between the umbilical vein and the RA.

The venous Doppler proved to be very useful in the assessment of fetal well being, particularly in the decompensated chronic fetal distress at the $2^{\text {nd }}$ and $3^{\text {rd }}$ trimesters ${ }^{23,24}$. When the fetus undergoes myocardial failure, the blood flow has difficulty in crossing the RA because of the altered HR or the impaired ventricular filling. In this situation the fetal venous Doppler is altered; in the inferior vena cava, there is elevation of the reverse flow during atrial contraction, which increases its percentage beyond $10 \%$. In the umbilical vein, the venous pulsation appears because of the reduction in the velocity of flow. Under this circumstance of heart failure, in the ductus venosus, the notch during the atrial contraction may not be visualized (absence of flow), or the reverse flow may appear, similar to that which is seen in the inferior vena cava.

In 1993, Kiserud et al $^{25}$ studied 30 fetuses with cardiac alterations using the analysis of the ductus venosus blood flow velocity. Eighteen had congenital heart disease and two had supraventricular tachycardia. The important finding was the reduction in the velocity during atrial contraction in 19 cases (including reverse flow in 13 fetuses). The authors believe that the alteration in atrial contraction is a sensible marker to detect fetal hemodynamic changes, particularly when there is cardiac malformation involving ventricular function.

Montenegro et al ${ }^{1}$ studied the ductus venosus blood flow velocity waveform and the measure of NT in 65 fetuses between the $10^{\text {th }}$ and $13^{\text {th }}$ weeks of gestation. Of these fetuses, 17 were included in the case series due to NT $>3 \mathrm{~mm}$. Five trisomies ( 4 cases of Down's syndrome and one trisomy 18) were detected. In the 12 remaining cases, the fetal karyotype was normal. No cytogenetic study was performed in the 48 cases that had NT <3mm; at birth, however, these newborn babies were normal, at least in relation to the phenotype. In regard to the ductus venosus, only those 5 cases of chromosome abnormalities had alteration in the Doppler velocimetry. The only velocimetric parameter that underwent alteration was the velocity of flow during atrial contraction, $<2 \mathrm{~cm} / \mathrm{s}(\mathrm{p}<0.001)$. The authors believe that both the increase in the NT and the velocimetric alteration of the ductus venosus occur due to a heart problem. They also believe that the Doppler alteration can reduce the incidence of false-positive results in the measurement of NT in the screening for chromosomal abnormalities and heart diseases, since the Doppler of the ductus venosus may detect early alterations in the fetal heart.

Matias et $\mathrm{al}^{26}$ reported alterations of the venous return (ductus venosus, inferior vena cava and umbilical vein) in 3 fetuses with increased NT between the $12^{\text {th }}$ and $13^{\text {th }}$ weeks of gestation and chromosomal and cardiac abnormalities revealed by cytogenetic study of the amniotic fluid obtained through amniocentesis.

The first case was a fetus of $73 \mathrm{~mm}$ of crown-rump length (CRL), with an NT of $4 \mathrm{~mm}$, urinary bladder dilation and heart rate of $165 \mathrm{bpm}$. The Doppler velocimetry showed increase of the reverse flow in the inferior vena cava, presence of reverse flow in the ductus venosus during atrial contraction, and pulse in the umbilical vein. The karyotype revealed trisomy 13 . In the anatomicopathological study, the biometrical parameters consisted of a fetus of 14 weeks, even though the pulmonary maturation was compatible with $16 / 17$ weeks, suggesting retarded intrauterine growth and with the following malformations: cleft lip, polydactyly, microcolon, moderate hydronephrosis and megacystis. The liver and heart exhibited microcalcifications and recent and old ischemic lesions, compatible with myocardial infarction. In the heart, these lesions were mainly subendocardial and localized in the RV. No major cardiac anomaly was detected.

The second fetus had an NT of $5.3 \mathrm{~mm}$ detected at the $12^{\text {th }}$ week of gestation. The CRL was $46 \mathrm{~mm}$, compatible with 11 weeks. The HR was 127 bpm. Ultrasonography revealed omphalocele and defect of the atrioventricular septum. Doppler showed pulsed flow in the umbilical vein and reverse flow in the ductus venosus and atrial contraction. The cytogenetic study revealed trisomy 18 . The anatomicopathological findings confirmed the ultrasonographic evidence and also revealed dysplasia of the pulmonary valve.

The third case was a fetus of a 28 -year-old pregnant woman (the oldest of the three cases). The routine ultrasonographic exam at the $12^{\text {th }}$ week of gestation revealed NT of $10 \mathrm{~mm}$ and a complete defect of the atrioventricular septum. HR was 147 bpm. Doppler showed increase in the reverse flow in the inferior vena cava and absence of flow in the ductus venosus during atrial contraction. The karyotype was compatible with trisomy 21 . The anatomicopathological study confirmed the septal defect and also demonstrated other minor alterations common to Down's syndrome. 
According to Kiserud et $\mathrm{al}^{27}$, the alterations in the flow of the umbilical vein, of the inferior vena cava and of the ductus venosus reveal increase in the ventricular pressure during the end-diastolic phase and the atrial contraction. Hecher and Campbell ${ }^{12}$ stress that the peripheral vascular resistance (like the increase in the placentary resistance) has a great influence in the venous return and in the filling pattern of the right heart.

In regard to the ductus venosus, reduction in the velocity of blood flow in this vessel during atrial contraction is associated with retarded intrauterine growth ${ }^{27}$, cardiac malformation ${ }^{1,25,26}$ and chromosomal abnormalities ${ }^{1,26}$.

\section{Comments}

The measurement of NT is considered a very useful method in the screening for chromosomal abnormalities ${ }^{7,8}$. Some authors, such as Montenegro et $\mathrm{al}^{1}$, accept the theory that the increase in NT is due to an early cardiac defect. Therefore, the method can also be used to screen for these anomalies.

Alteration in the blood flow velocity during atrial contraction in the cases of chromosomal abnormalities reported by Montenegro et al ${ }^{1}$ may reveal indirectly an early failure in the fetal heart (alteration in atrial contraction or ventricular compliance), even though these results are preliminary and unique in the reviewed literature.

The combination of NT and Doppler assessment of the ductus venosus can be very useful in the detection of early cardiac defects. According to Souka and Nicolaides ${ }^{28}$, the association of severe heart diseases with thickened NT is around $2 \%$. This prevalence is similar to that of the group with diabetes mellitus and the group of women with previous history of heart disease in their children. In these two groups, fetal echocardiography is formally indicated. In the same way, there is a formal indication for study of the fetal heart when NT is thickened between the $10^{\text {th }}$ and $14^{\text {th }}$ weeks of gestation. Echocardiography should be performed later, in the second trimester. Currently, there are neither enough facilities nor specialists to support this new demand, since there is evidence that $5 \%$ of the fetuses have thickened NT. One can suppose that Doppler assessment of the ductus venosus and the measurement of NT could reduce this demand for fetal echocardiography when the Doppler assessment is normal.

The results up to now do not allow the indication of the method (NT associated with Doppler assessment of the ductus venosus) for the prediction of cardiac dysfunction. A multicenter study with a large screening protocol is mandatory.

\section{References}

1. Montenegro N, Matias A, Areias JC, Castelo S, Barros H. Increased fetal Nuchal Translucency: possible involvement of early cardiac failure. Ultrasound Obstet Gynecol 1997; 10: 265-8.

2. Eik-Nes SH, Brubakk AO, Ulstein MK. Measurement of human fetal blood flow. Br Med J 1980; 280: 283-4.

3. Gill RW, Trudinger BJ, Garrett WJ, Kossoff G, Warren PS. Fetal umbilical venous flow measured in uterus by pulsed Doppler and B-mode ultrasound in normal pregnancies. Am J Obstet Gynecol 1981; 139: 720-5.

4. Griffin D, Cohen-Overbeek T, Campbell S. Fetal and utero-placental blood flow. In: Campbell S (ed). Ultrasound in Obstetrics and Gynecology: Recent Advances. Clinics Obstet Gynecol 1983; 10: 565-602.

5. Kiserud T, Eik-Nes SH, Blass HG, Hellever LR. Ultrasonographic velocimetry of the fetal ductus venosus. Lancet 1991; 33: 1412

6. Wladimiroff JW, Seelen JC. Fetal heart action in early human pregnancy. Development of fetal vagal function. Eur J Obstet Gynecol 1972; 2: 55-63.

7. Nicolaides KH, Brizot ML, Snijders RJM. Fetal nuchal translucency: ultrasound screening for fetal trissomy in the first trimester of pregnancy. Br J Obstet Gynecol 1994; 101:782-6.

8. Pandya PP, Snijders RJM, Johnson SP, Brizot ML, Nicolaides KH. Screening for fetal trisomies by maternal age and fetal nuchal translucency thickness at 10-14 weeks of gestation. Br J Obstet Gynecol 1995; 102: 957-62.

9. Souka AP, Snijders RJM, Novakov A, Soares W, Nicolaides KH. Defects and syndromes in chromosomally normal fetuses with increased nuchal translucency thickness at 10-14 weeks of gestation. Ultrasound Obstet Gynecol 1998; 11: 391-400.

10. Hyett J, Moscoso G, Papapanagiotou G, Perdu M, Nicolaides KH. Abnormalities of the heart and great arteries in chromosomally normal fetuses with increased nuchal translucency thickness at 11-13 weeks of gestation. Ultrasound Obstet Gynecol 1996; 7: 245-50.

11. Wladimiroff JW, Huisman TWA, Stewart PA. Intracerebral, aortic and umbilical artery flow velocity waveforms in the late first trimester fetus. Am J Obstet Gynecol 1992; 166: 46-49.
12. Hecher K, Campbell S. Characteristics of fetal venous blood flow under normal circumstances and during fetal disease. Ultrasound Obstet Gynecol 1996; 7 : 68-83.

13. Huisman TW, Gittenberger-De Groot AC, Wladimiroff JW. Recognition of a fetal subdiaphragmatic venous vestibulum essential for fetal venous Doppler assessment. Pediatr Res 1992; 32: 338-41.

14. Montenegro CAB, Rezende Filho J, Silva LGP. Centralização Fetal. Femina 1994; 22: 203-15.

15. Pearson AA, Sauter RW. Observations on the phrenic nerves and the ductus venosus in human embryos and fetuses. Am J Obstet Gynecol 1971; 110: 560-5.

16. Rezende J, Orlandi O. O feto. In: Rezende J. Obstetrícia. $5^{\text {a }}$ ed. Rio de Janeiro. Guanabara Koogan, 1998: 51.

17. Huisman TWA, Stewart PA, Wladimiroff JW. Ductus venosus blood flow velocity waveform in a human fetus a doppler study. Ultrasound Med Biol 1992; 18: 33 .

18. Gennser G. Fetal ductus venosus and its sphincter mechanism. Lancet 1992; 339: 132.

19. Montenegro N, Matias A, Areias JC, Barros H. Ductus venosus revisited: a Doppler blood flow evaluation in first trimester of pregnancy. Ultrasound Med Biol 1996; 23: 171-6.

20. Wladimiroff JW, Huisman TA. Venous return in the human fetus. In: Kurjak A, Chervenak A. The Fetus as a Patient. $1^{\mathrm{a}}$ ed. London: The Parthenon Publish Group, 1994; cap. 34: 425-34.

21. Trudinger BJ, Cook CM, Giles WB, Connely A. Umbilical artery flow velocity waveforms in high-risk pregnancy: randomized controlled trial. Lancet 1987; 2: 188-90.

22. Van Splunder P, Huisman TWA, Ridder MAJ, Wladimiroff JW. Fetal venous and arterial flow velocity wave forms between eigth and twenty weeks of gestation. Pediatr Res 1996; 40: 158-62.

23. Indik JH, Chen V, Reed KL. Association of umbilical venus with inferior vena cava blood flow velocities. Obstet Gynecol 1991; 77: 551.

24. Rizzo G, Arduini D, Romanini C. Inferior vena cava flow velocity waveforms in appropriate and small-for-gestation-age fetuses. Am J Obstet Gynecol 1992; 166: 1271. 
Murta et al

Arq Bras Cardiol

Alterations of fetal cardiac function

volume $72,\left(n^{\circ} 6\right), 1999$

25. Kiserud T, Eik-Nes SH, Hellever LR, Blass HG. Ductus venosus blood velocity changes in fetal cardiac diseases. J Matern Fetal Invest 1993; 3: 15-20.

26. Matias A, Montenegro N, Areas JC, Brandão O. Anomalous fetal venous return associated with major chromosomopathies in the late first trimester of pregnancy. Ultrasound Obstet Gynecol 1998; 11: 209-13.

27. Kiserud T, Eik-Nes SH, Blass HG, Hellever LR, Simensen B. Ductus venosus blood velocity and the umbilical circulation in the seriously growth-retarded fetus. Ultrasound Obstet Gynecol 1994; 4: 109-14.

28. Souka AP, Nicolaides KH. Diagnosis of fetal abnormalities at the 10-14 week scan. Ultrasound Obstet Gynecol 1997; 10: 429-42. 